\title{
The Innovation of Communication Planning Idea-—Based on the Background of the Application of Artificial Intelligence in Media
}

\author{
Feng Liu \\ College of Publishing, University of Shanghai for Science and Technology, Shanghai, China
}

Email address:

panda197@163.com

To cite this article:

Feng Liu. The Innovation of Communication Planning Idea_-Based on the Background of the Application of Artificial Intelligence in Media. International Journal of Intelligent Information Systems. Vol. 6, No. 6, 2017, pp. 85-89. doi: 10.11648/j.ijiis.20170606.13

Received: September 17, 2017; Accepted: October 10, 2017; Published: December 11, 2017

\begin{abstract}
The idea of planning of communication is getting lost in the context of media convergence, but a hope of improving the humanity of news through technology emerged because of the arrival of the era of intelligent communication. There are still a lot of shortcomings in the current algorithm used in news production, however, intelligent communication has become an irreversible trend, journalists need to change the planning idea as soon as possible. This paper discusses this problem from the following aspects such as driving technology with humanity, from catering to guiding, diversification of news forms, striding across from information attributes to intelligent attributes.
\end{abstract}

Keywords: Artificial Intelligence, Planning Idea, Humanity, Technology

\section{Introduction}

The development of media convergence promotes the rapid increase of publicity contents, whose forms are continuously enriching. However, there have been many problems in the development to media industry, so that many practitioners can be trapped in discomfort or get lost in the process of communication planning. The traditional planning concept can hardly play its role in media production if it can't keep up with the ecology of communication. In ecological transformation period of communication convergence, the lost of communication planning philosophy can be mainly reflected as the following three aspects.

Firstly, the scope of communication planning concept continues to expand. The traditional communication planning mainly concentrates on the content production link. The "good content" is the target of planning activities. The production of communication is less affected by the mode of communication and profit model etc. However, in ecological transformation period of communication convergence, the role of emerging technology in the communication and production fields continues to enlarge, which can speed up the change of media's communication ecology environment. "Communication content, communication mode, communication channels and even communication system have undergone a fundamental change. [1]" Therefore, the form and interactive mode of media works shall be fully considered in communication production link. These are mostly thought and controlled by operation managers. However, now producers, communicators and technical personnel are all required to have this idea and skills, so as to meet the requirement of increasingly complex communication environment on products.

Secondly, the concept of communication planning is becoming increasingly rich. While expanding from production to communication and operation, the communication planning concept under the convergence ecology has broken through the single news layer, in which wisdom shall be learned from other level sand dimensions. For example, based on reporting mechanism different from the tradition alone, data journalism is promoting the development of media convergence. "Media may not be able to control the entire topic operation, which shall rely on external cooperation. Some enterprises and research institutions have more data and more excellent data analysis skills than the media, who often become the target of media cooperation. [2]" It can be said that whether we can fully utilize the scientific factors outside the media will to a large extend determine the position of a media in the future 
media industry.

Thirdly, how to control the orientation of communication planning in the age of intelligence. In the era of artificial intelligence, efficiency is the primary goal of every media organization in survival sense. However, under the pressure of surviving, how to extend and optimize the communication planning concept, and maintain the influence and leader ship of mainstream news media tests operator's wisdom; in addition, various new forms of news types will gradually develop, for example, the robot writing has been applied in sports, finance and other production activities. Sports and financial newswriting focus more on there presentation of basic information and objective data, which is the advantage of robots. However, how to guide the values and expressideasinthenewshasbecomeanewproblemconfrontingpr actitioners. As a result, the trapped communication planning concept must confront a new dimension of challenges.

\section{Discussion}

"In the future media production, how to accurately locate the human is unknown. Therefore, we shall constantly adjust our thinking with the continuous development of communication technology. [3]" digital technology is a fundamental driving factor in the process of convergence development. The new forms, such as robot news, VR news, and sensor news, gradually develop. Content production and intelligence degree of communication increase greatly. "If the media development in recent ten years aims to seek a competitive advantage in the digital advancement, a new competitive advantage will be formed in intelligent development in the following ten years. [4]" compared with digitizing, the advantage of intelligence lies in its ability to independently learn and evolve. The basis for the development of artificial intelligence is that AI gradually has the function of human learning, understanding, analyzing and processing information. AI will gradually go beyond the simple data type information processing and can control the cultural in formation, so the production logic and requirements that are different from Digital Era may also occur in the era of artificial intelligence.

At present, the typical representative of intelligent media production is the robot journalism. Based on a large amount of acquired data, journalism robot can automatically, quickly and accurately complete the news writing according to certain algorithm programming. "The so-called journalism robot is actually a set of software or programming language. The algorithm refers to the designed computer program containing a series of complicated mathematical rules to solves pacific problems through the preset steps. [5]" Currently, both overseas Associated Press, Bloomberg Finance, Forbes, Losangeles Times, and the domestic Xinhua news agency, Tencent, Daily Head lines are stepping up the layout, so as to quickly seize the initiative for the development of robot journalism. However, the robot journalism is still in the relatively primary stage of information and language convergence, stitching etc. It now can complete some information content production in some fields with strong data structure, such as sports and finance etc. Even so, the journalism robot can replace the news journalists in many positions, which make many practitioners worried and even go panic.

The development of artificial intelligence will indeed eliminate some practitioners, which however does not necessarily urge technology to replace human. Journalism robot can provide a lot of assistance to journalists, which can liberate journalists from repetitive work, so that the journalists can spend more energy in thinking communication planning. This undoubtedly creates a huge space for the improvement of news production quality. On the other hand, communication production in the era of artificial intelligence has self learning potential, such as the pioneer of American robot journalism narrative science company. In early period, thousands of events news was completed by robots. However, robots have a preference for winners in writing, and lay too much criticism on the losers; then the company discovered the problem and improved the algorithm, so that robots cannot only adapt to different customer requirements, but also can produce news works in different writing styles. There is still much room for robots' intelligent learning ability in robot journalism, so experts predict that robot journalists will win the Pulitzer Prize in the future.

"The development of intelligent media enables us to further understand that the essence of all life is only the symbol operation and information spread. [6]" Through the intelligent algorithm optimization, the intelligence degree of media production is surging, and "Alpha Go" in media fields must emerge, which can reflect the basic logic of media production and development in era of intelligence. For along time, "antithesis" of technology and humanity has been in a dominant position, which can also be reflected in many comments about the robot, claiming that robot writing lacks humanity "temperature", "in order to increase the attraction, appeal, affinity and influence of news, we must collect and process the warm report content. [7]" With the development of artificial intelligence, the "unity" between technology and humanity will gradually become dominant, and technology will become an effective tool for enhancing human values and "temperature" of media works.

\section{Result}

Technology "temperature" is gradually increasing, but never shall we ignore that the "antithesis" between "technology" and "humanities" will always exist. The increasingly powerful algorithm is basis of constantly improved spread intelligence. However, the algorithm in the growth stage has some short comings, which is the key to restrict the development level of artificial intelligence. In order to tackle this problem, the necessity to reshape communication concept planning will be prominent. Taking the logic of the current journalism robot algorithm as an example, through refining and simplifying the process of 
human news writing, it can automatically form the writing manuscript by the programming and modeling methods. Although the robot writing model can be constantly optimized to improve the quality of the manuscript writing based on big data analysis, it can hardly reach the level of human journalists in terms of human expression in short terms.

Briefly speaking, the intelligent production is currently characterized by automated production, which is the embodiment to find us trial intelligent production and the main trend of production from human to equipment in the production process. Intelligent process of industrial production line gradually liberates human physical labor, but intelligent industrial production does not have the ability of thinking. Therefore, the humanistic ideas reflected in industrial products derive from the designers' settings of the algorithm and program. Taking "Face book bias incident" as an example, Face book's "trend topic" module determines the content order through the algorithm, which may press conservative media, thus being criticized by peers and the public; although the algorithm is objective as technology, it is based on subjective design. The media production will get trapped if the design concept deviates.

Technology can help the media effectively grasp the trend of information spread and public opinion, which however is not the only dimension. "The cyber space not only contains the information flow, but also emotional flow. [8]" it can be predicted that, big data, in-depth machine learning, neural science and other technologies will be widely applied in spread. However, the span from "information flow" to "emotional flow" requires a process, which will also undergo the innovation of communication planning concept and methods. A study of social media and personal happiness (well-being) in University of California explored the influence of social media information's content presentation and mode of communication on user's happiness, such as Face book etc., believing that poorly designed algorithm will exert a negative effect on audience's feelings [9]; Neil Thurman of London University also questioned the application of automation method in court news report, who held that this way can hardly scientifically and comprehensively control politics, investigation process, inter personal relationship and other information [10].

The traditional planning concept can hardly meet the need of artificial intelligence in many aspects. However, the current focus is not whether the journalist will be replaced, but how to "tame" intelligent technology, thus making it become a powerful weapon to promote the media humanity "temperature". This is the starting point of reshaping communication planning concept. For example, Face book carried out political bias training for staff to solve the problem of bias incident. Through the remedy of theory, Face book tried to avoid the unreasonable application intelligent technology. "No matter how the algorithm is accurate, the media should have its own values. [11]" artificial intelligence is based on highly developed technology. Even so, the technology may have its deficiencies in different degree. For example, the scope of robot algorithm application continues to expand in the media production fields. The key solution is to form effective guidance of humanity to technology from operation concept level.

\section{Conclusion}

The "intelligence" feature of communication production is becoming increasingly obvious, we should prospectively head for "intelligent" communication trends, absorb excellent experience in "artificial" production process, base on the communication production requirements of "industrialization", so as to actively promote the transformation from the traditional communication planning concept to intelligent planning concept. The concept innovation shall be adopted to promote the development of communication production, so as to set up scientific algorithms and rule procedure for the communication's automated industrial production. In this case, we can actively confront the challenges of the intelligent era to communication production.

Firstly, tame technology by humanities and urge the technology to serve communication. It's necessary to explore the use standard of intelligent algorithm in the content production and communication process, and design the direction, principle and path for in-depth selflearning of intelligent algorithm, so that the intelligent technology can further develop in the humanistic spirit. On March 18, 2014, the Quakebot of "Losangeles Times" web produced news with in 3 minutes after earth quake occurred in Losangeles. This robot made Losangeles Times become the first media who issue earth quake news while safe guarding journalists' personal safety [12]; Zubiaga from the University of Warwick in England intelligently collected data by the technology, and improved the ability to real-time recognize rumors by upgraded machine learning technology, so as to purify communication environment [13]. These are just relatively simple applications of intelligent technology. We can see that the application of technology can reflect the humanistic care and serve for communication. Therefore, planners should explore the application of this concept in communication.

Secondly, it's imperative to shift the starting point of personalized service users from catering to guiding. Intelligent technology, especially the big data technology, can realize precise user portrait, and provide personalized information service for different users. Google funded a large British news office to develop an intelligence software, which can monthly produces thirty thousand pieces of news. Five human journalists will produce news in terms of health, crime and employment etc. based on open government database and story template, so as to efficiently serve different target groups. The technical assistance is adopted to meet the individual needs. In the process of planning, we shall clearly know users in stead of gaining market returns by catering. We ought to effectively guide and help users to obtain more nutritional and warm information, thus obtaining 
humanistic nourishment. Some "small but beautiful" content can be presented in front of users. "The combination of algorithm and human reflects respect and the pursuit of specialized spirits and quality news. [14]" from understanding users to figuring out user hope and matching growth, personalized production and push can provide valuable services for users, which reflects the advancement of the communication planning concept.

Thirdly, communication pattern's inclusive, diversified and integrated development. In communication production, diversified and integrated writing mode and style can be achieved. Content production should learn from highly inclusive, entertaining and information presentation mode. Certainly, the cooperation between producers and engineers shall be strengthened in the planning process, so that the algorithm evolution can meet the needs of media form convergence. For example, the Manuel Ruder team of Freiburg University in Germany applied algorithm to extract the style of Van Gogh, Monck and other artists, which was used for the video display, allowing film scene of The ICE AGE to be set in painter's style [15]; Yazdani of Malaysia University of Putra found that feature weighted methods can play an important role in sentiment classification, which can predict the economic situation in a certain range [16]. The communication planning concept planning in the intelligent age should contain and learn from various kinds of art and cultural expressions based on intelligent technology, which can enhance its humanistic value while improving its production efficiency.

Fourthly, the transition from information attributes to intelligent attributes. As the artificial intelligence develops, "the Internet no longer serves as the role of the information warehouse and mechanical porter, but become more intelligent information manager. [17]" news will also go beyond the current information communication function and be equipped with stronger intelligent attributes, thus increasing the humanistic temperature for more intelligent scenes. Water and air quality testing instrument and others ensing devices can be creatively used in the investigation. Technological innovation has become the key field of news communication [18]. Sensor news emerges recently. The formation mechanism of this intelligent news is based on technology innovation, which can bring the news information that can hardly be obtained and sensed by traditional media era; "headline lab" director Li Lei once said, "Daily Headlines" are injecting emotional motivation into robots, so as to handle the high quality content creation and other issues [19]. Certainly, it is necessary to refine the communication planning concept from more macro perspective and more interdisciplinary perspective, so as to materialize this intelligent attributes as soon as possible.

"The development of artificial intelligence has turned the global village into a global brain. [20]" in which intelligent technology serves as the driving force for global village's evolution to global brain. The evolution from the "link" to the "wisdom" provides basic conditions for the "humanity" embodiment of communication. We shall consider how to improve the intelligence degree of technology application as soon as possible, so that it can play a greater role in increasing "humanity" temperature. Application of intelligent technology in the field of communication is increasingly deepening, the relationship between traditional manual writing and intelligent production has become a hot topic. "Pete Clifton, editor in chief of the British press association believes that the skilled human journalists are still important. However, "the artificial intelligence can reach the news quantity that can hardly be realized by manual labor, [21]" Two production modes are irreplaceable. Moreover, when currently emphasizing the influence of artificial intelligence on the media industry, we don't require all practitioners must be equipped with the algorithm and programming skills. Instead, all people shall grasp its operational principle and law as soon as possible, so as to technically keep a breast with the demands proposed by the era of artificial intelligence.

\section{Acknowledgements}

This paper is supported by shanghai philosophical and social science foundation project "Communication strategy of shanghai regional culture based on mobile Internet" (2016EXW001) and "The IP communication strategy of Shanghai-school culture in the mobile Interne tEra" (the "climbing plan" of USST).

\section{References}

[1] Shen Hao, Luo Chen. Data News: Historical Prospect From The Perspective Of Modernity, [J]. University of Journalism, 2016(2), p1.

[2] Fang Jie, Hu Yang, Fan Di. Data News Practice In The Eyes Of Media Personnel: Value, Path And Prospect, [J]. University of journalism, 2016(2), p16.

[3] Peng Lan. Structural Changes Of News Information Resources In The Era Of Big Data And Its Influences [J]. Chinese Radio \& TV, 2013(7), p11.

[4] LvShangbin, LiuYifu. Media Intelligence And Intelligent Media [J]. contemporary communication, 2016(4), p4.

[5] Deng Jianguo. Robot News: Principles, Risks, And Impacts [J]. Journalists, 2016(9), p11.

[6] Zhang Lei. From Global Village to Global Brain-Fusion Of Intelligent Media To Life [J]. contemporary communication, 2008(6), p10.

[7] Sun Ying. Robot news: a News Production Model Based On Big Data. Friends of Editors, 2016(3), p95.

[8] Ding Han qing, Liu Nian. Academic Field Of Emotion Recognition Research, [J]. University of journalism, 2017(2), p119.

[9] Panger Galen, "Reassessing the Face book experiment: critical thinking about the validity of Big Data research," Information, Communication \& Society. 8(2016): p1108-1126. 
[10] Nadeem Badshah, "And here is the automated news generated by robot," Times, The (United Kingdom). 07 Jul. 2017: p5.

[11] YanXi. Besides Algorithm, We Still Need The News With Attitudes [N]. Internet Weekly, 20160605, p44.

[12] Sun Ying. Robot News: A News Production Model Based On Big Data. [J] Friends of editors, 2016(3), p95.

[13] Zubiaga Arkaitz, Liakata Maria, Procter Ro, “Analysing How People Orient to and Spread Rumours in Social Media by Looking at Conversational Threads," PLoS ONE. 03 Apr. 2016: p1-29.

[14] Zhang Zhian, Zeng Zijin. From Media Plat form To Plat form Media, [J]. Journalist, 2016(1), p21.

[15] Here Comes The Robot! Japanese Insurance Giant Replaces Employee 30\% With AI [EB/OL]

Http://news.china.com/international/1000/20170103/3013450 7_all.html.
[16] Yazdani Sepideh Foroozan, Murad Masrah Azrifah Azm, Sharef Nurfadhlina Mohd, "Sentiment Classification of Financial News Using Statistical Features," International Journal of Pattern Recognition \& Artificial Intelligence. 03(2017): p1.

[17] Peng Lan. Evolution Of Connectivity-The Basic Logic Of Internet Evolution, [J]. international press, 2013(12), p17.

[18] Coll Steve, "Finding new ways to follow the story," Columbia Journalism Review. Fall 2016: p21-23.

[19] Li Lei, Today's Headlines Robot-Dialogue, Q\&A, news creation, artificial intelligence has been omnipotent? [EB/OL] Http://mt.sohu.com/20161020/n470766686.shtml.

[20] Zhang Lei. From Global Village To Earth Brain-Fusion Of Intelligent Media To Life [J]. contemporary communication, 2008(6), p10.

[21] Nadeem Badshah, "And here is the automated news generated by robot," Times, The (United Kingdom). 07 Jul (2017): p5. 